\title{
Presentación
}

\section{Los aprendizajes no-académicos en las prácticas educativas}

JuAN CARlos Silas CaSillas*

SUSANA CUEVA DE LA GARZA**

(COORDINADORES)

$\mathrm{H}$ istoriadores, sociólogos, antropólogos, educadores e interesados en el estudio de las sociedades han documentado que, desde la antigüedad, todas las agrupaciones humanas han contado con diferentes mecanismos, instituciones y prácticas educativas para formar a sus ciudadanos, especialmente los más jóvenes. En ocasiones se trata de sistemas educativos complejos, diferentes modos de acceso, transiciones entre los niveles, salidas laterales de acuerdo con los intereses de los individuos, y perfiles de ingreso y egreso establecidos con claridad. Otras sociedades han construido esquemas sencillos que se componen de unos cuantos niveles genéricos que son validados por la autoridad educativa. Incluso, algunas agrupaciones humanas tienen iniciativas educativas independientes, con sus propios fines y medios, que son reconocidos por las comunidades o los gremios laborales y no por autoridades civiles.

La literatura profesional da cuenta de cómo las sociedades complejas y funcionalmente diferenciadas tienen sistemas educativos especializados que parecen responder a las expectativas económicas de sus sectores productivos mediante una interconexión estrecha entre sus componentes sistémicos. Por otra parte, dada la fuerte influencia de los sistemas educativos de los países económica, social o culturalmente poderosos en la toma de decisiones de los organismos multilaterales e incluso en los sistemas educativos menos fuertes, parece existir una tendencia de isomorfismo que empuja a algunas naciones a modificar su estructura vernácula de realizar educación para adoptar modelos que han demostrado valía en contextos diferentes. Esto ha sido en particular notorio en los últimos años del siglo XX y en las primeras décadas del XXI cuando los Estados nacionales y sus sistemas educativos tienden a orientarse hacia competencias medibles y comparables $y$, en este sentido, toman una forma similar en sus procesos y los elementos que se usan para valorar su impacto y logro.

En los años recientes ha sido común encontrar estudios que analizan de manera comparativa los logros de individuos, instituciones y sistemas educativos en aspectos como habilidades matemáticas, dominio de competencias en lengua materna u otros idiomas de trascendencia global, pensamiento científico, entre otros. Ejemplos tangibles en el ámbito internacional son pruebas como Programme for International Student Assessment, desarrollado y publicitado intensivamente por

Recuperado de: https://sinectica.iteso.mx/index.php/SINECTICA/article/view/1196 doi: 10.31391/S2007-7033(2020)/0055-001

\footnotetext{
* Doctor en Educational Policy and Leadership por la Universidad de Kansas, EUA. Profesor e investigador del Departamento de Educación del Instituto Tecnológico y de Estudios Superiores de Occidente (ITESO). Miembro del Sistema Nacional de Investigadores desde 2003. Líneas de investigación: balance-público privado en la educación superior, relación entre las instituciones educativas y la comunidad, interculturalidad en la educación superior y pensamiento científico en alumnos universitarios. Correo electrónico: silasjc@iteso.mx

** Doctora en Educación por el ITESO. Coordinadora del Doctorado Interinstitucional en Educación sede León. Líneas de investigación: concepciones del compromiso social en las prácticas docentes universitarias. Correo electrónico: susana. cuevas@iberoleon.mx
} 
la Organización para la Cooperación y el Desarrollo Económicos; el estudio de las Tendencias en Matemáticas y Ciencias (Trends in International Mathematics and Science Study), llevado a cabo por la Asociación Internacional para la Evaluación del Rendimiento Educativo; o el Teaching and Learning International Study. En el contexto continental está el Laboratorio Latinoamericano de Evaluación de la Calidad, con sus estudios comparativos sobre el aprendizaje de las matemáticas, la lengua escrita y las ciencias naturales. En el ámbito mexicano podemos hablar del Examen para la Calidad y el Logro Educativo, la Evaluación Nacional de Logros Académicos en Centros Escolares y el Plan Nacional para la Evaluación de los Aprendizajes, los cuales han dejado de aplicarse.

En todo caso, lo relevante no es tanto el instrumento ideado para la medición, sino el acento puesto en evaluar y comparar los resultados a gran escala, lo cual, a pesar de sus posibles bondades, tiene un efecto pernicioso al eclipsar los aprendizajes noacadémicos de los actores involucrados. La atención especial otorgada a encontrar elementos para hacer comparaciones deja de lado los que no corresponden con lo prescrito de manera curricular e ignora logros que se obtienen a través de prácticas educativas no-formales o que tienen fines diferentes. Para algunos teóricos, estos "otros aprendizajes" se encuentran dentro del currículo oculto, es decir, son habilidades y competencias posiblemente no intencionadas de manera explícita (y, por lo tanto, fuera de los sistemas evaluativos) que, sin embargo, prosperan y tienen algún impacto formativo.

De esta manera, los aprendizajes que se dan en áreas como autoeficacia académica, motivación escolar y sentido que se otorga a los estudios, participación y formación ciudadana, hábitos de vida saludable, relaciones sociales, actitudes pro- o antisociales, capacidad de introspección, construcción de autonomía individual, trabajo colaborativo y un largo etcétera, al no ser objeto de valoración comparativa, quedan fuera de la mirada de académicos, sociedad civil y tomadores de decisiones.

El número 55 de Sinéctica agrupa una colección de sólidos artículos de investigación, escritos de manera minuciosa y fundamentados en evidencias empíricas, que ilustran experiencias relativas a esos aprendizajes que se quedan fuera de lo pautado y medido. Nuestra expectativa es que, con esta entrega, se inicie la producción académica sobre estos temas, por lo general confinados a los anecdotarios, y se contribuya al análisis, el debate y la reflexión sobre "los otros aprendizajes", sus características, prácticas y consecuencias.

Estimada lectora, estimado lector, esperamos que disfrutes los textos que integran esta edición y que nos acompañes en este "vuelo inaugural" hacia los "otros aprendizajes". 